\title{
Substance and Behavioral Addictions: Beyond Dependence
}

\section{Daria J. Kuss*}

International Gaming Research Unit, Nottingham Trent University, UK

The area of addiction research and therapy is on the move. The American Psychiatric Association's Work Group for the development of the upcoming revision plans major changes in the addiction field. In time for the publication of the fifth edition of the Diagnostic and Statistical Manual for Mental Disorders (DSM) in 2013, the Journal of Addiction Research and Therapy presents its special issue on Substance and Behavioral Addictions.

In the revised edition of the DSM, Substance-Related Disorders will be reconceptualized into "Addiction and Related Disorders" [1]. The disparity between addiction and dependence lies at the core of this reconceptualization. In fact, it might be more appropriate to refer to a return to the original terminology. It was only in 1964 that the World Health Organization decided to replace the diagnosis of "addiction" that was used until then with the seemingly more appropriate label "dependence" [2]. Dependence, it was assumed, was a more neutral term relative to the rather stigmatizing label of addiction [3]. Essentially, dependence refers to a physiological adaption to continued substance intake. The individual develops tolerance, requiring larger amounts of the substance to achieve the desired effect. Moreover, once use is reduced or discontinued, psychological, physiological and emotional withdrawal symptoms are experienced [4]. This "normal" physiological response does not necessarily indicate pathology and can likewise occur after using prescribed medications. Patients requiring pharmacological treatment are not actually addicted to their medication. Therefore, using the dependence label in this diagnostic context stigmatizes patients and it "is not only confusing and misleading, but it contributes to suffering" [3].

Addiction, on the other hand, denotes a chronic neurobiological disease that is linked to a deficiency in the individual's reward system [5]. It results in compulsive reward-seeking behaviors that are continued despite significant negative bio-psychosocial consequences and adverse effects on a variety of life domains [6].

With the new edition of the DSM, the revised category of "Addiction and Related Disorders" moves beyond a focus on withdrawal and tolerance (i.e., classical dependence symptoms), towards the strength of motivation for substance use and engagement in behavior as well as the lack of control to resist craving [7]. Not only does this reconceptualization destigmatize patients treated with prescribed medicines, but it also allows for the inclusion of both, substance-related as well as behavioral addictions in the proposed categorization scheme.

Researchers have long called for studying behavioral addictions in more breadth and depth in order to discern whether there is adequate evidence to support their inclusion in the revised diagnostic manuals [8]. It appears that these efforts have come to fruition now. Pathological Gambling, formerly subsumed under the exceptionally heterogeneous group of Impulse-Control Disorders Not Otherwise Specified, will now be classed as addiction. "Gambling Disorder", as it will be called, shares a variety of commonalities with substancerelated addictions. These include physiology [9], such as the activation of a similar brain circuitry [10], etiology [11], comorbidity [12], clinical expression [13], and treatment [14]. As a consequence of pathological gambling being classed as actual addiction, it appears reasonable to claim that other behavioral addictions may follow suit. For instance, the APA discusses the inclusion of "Internet Use Disorder" as potential mental health problem that requires further research in the upcoming revision of the DSM (2012).

Based on the empirical evidence of similarities between substance and behavioral addictions, Shaffer and his colleagues (2004) developed a syndrome model of addictions that encompasses both substance and behavioral addictions. They argue that addictions share neurobiological and psychosocial precursors that increase vulnerability for pathogenesis. A premorbid addiction syndrome will develop only if the precursors are combined with the exposure to, interaction with and a resulting subjective shift due to engagement in the addictive behavior. The latter requires both immediate precursors (i.e., life events) and repeated rewarding engagement in the addictive behavior for an addiction to become manifested. Once manifested, addictions vary in distinctive expression (i.e., substance-related and behavioral) and unique negative consequences (i.e, liver cirrhosis in alcoholics or gambling debt in pathological gamblers) [15]. However, addictions share a variety of biological and psychosocial expressions and ramifications, such as symptoms and treatment [16]. The syndrome model of addiction moves beyond the dependence paradigm to embrace addiction as a disease that encompasses both substance-related and behavioral addictions. In order for an addiction to be expressed, the occurrence of symptoms such as tolerance and withdrawal is not sufficient. At the same time, the addiction perspective is less diffuse than the dependence paradigm in that the former necessitates the presence of psychosocial commonalities (including symptoms) in addition to the biological similarities to demarcate this psychopathology.

The purpose of viewing and treating certain behaviors as potentially addictive is not to pathologize the engagement in pleasurable pastime activities. Instead, the aim is to take seriously the individuals who suffer from the lack of control over their behaviors, to increase knowledge of a yet insufficiently explored area, and to provide help for those who need it. Conclusively, the addition of behavioral addictions to the diagnostic framework must be seen as a progressive step towards the improvement of both clinical practice as well as research in the area of addiction.

\section{References}

1. American Psychiatric Association (2012) DSM-5: The future of psychiatric diagnosis. DSM-5 development.

2. Berridge V, Mars S (2004) History of addictions. J Epidemiol Community Health 58: 747-750.

*Corresponding author: Daria J. Kuss, MBPsS Doctoral researcher, International Gaming Research Unit, Nottingham Trent University, Nottingham NG1 4BU, UK, Tel: + 44 - 78911194 90; E-mail: daria.kuss@ntu.ac.uk

Received May 05, 2012; Accepted May 07, 2012; Published May 09, 2012

Citation: Kuss DJ (2012) Substance and Behavioral Addictions: Beyond Dependence. J Addict Res Ther S6:e001. doi:10.4172/2155-6105.S6-e001

Copyright: (c) 2012 Kuss DJ . This is an open-access article distributed under the terms of the Creative Commons Attribution License, which permits unrestricted use, distribution, and reproduction in any medium, provided the original author and source are credited. 
3. O'Brien CP, Volkow N, Li TK (2006) What's in a word? Addiction versus dependence in DSM-V. Am J Psychiatry 163: 764-765.

4. American Psychiatric Association (2000) Diagnostic and statistical manual for mental disorders, Fourth Edition: DSM-IV-TR®. American Psychiatric Pub, Washington, D. C.

5. Comings DE, Blum K (2000) Reward deficiency syndrome: Genetic aspects of behavioral disorders. In Cognition, emotion and autonomic responses: The integrative role of the prefrontal cortex and limbic structures. Elsevier 126: 325-341.

6. American Society of Addiction Medicine (2012) The voice of addiction medicine.

7. Kalivas PW, Volkow ND (2005) The neural basis of addiction: A pathology of motivation and choice. Am J Psychiatry 162: 1403-1413.

8. Potenza MN (2006) Should addictive disorders include non-substancerelated conditions? Addiction 101: 142-151.

9. van Eimeren T, Ballanger B, Pellecchia G, Miyasaki JM, Lang AE, et al. (2009) Dopamine agonists diminish value sensitivity of the orbitofrontal cortex: A trigger for pathological gambling in Parkinson's disease? Neuropsychopharmacology 34: 2758-2766.
10. Clark L, Lawrence AJ, Astley-Jones F, Gray N (2009) Gambling near-misses enhance motivation to gamble and recruit win-related brain circuitry. Neuron 61: 481-490.

11. Hopley AA, Nicki RM (2010) Predictive factors of excessive online poker playing. Cyberpsychol Behav Soc Netw 13: 379-385.

12. Griffiths M, Wardle H, Orford J, Sproston K, Erens B (2010) Gambling alcohol, consumption, cigarette smoking and health: Findings from the 2007 British Gambling Prevalence Survey. Addiction Research and Theory 18: 208-223.

13. Petry NM (2006) Internet gambling: An emerging concern in family practice medicine? Fam Pract 23: 421-426.

14. Hodgins DC, el-Guebaly N (2000) Natural and treatment-assisted recovery from gambling problems: A comparison of resolved and active gamblers. Addiction 95: 777-789.

15. Shaffer HJ, LaPlante DA, LaBrie RA, Kidman RC, Donato AN, et al. (2004) Toward a syndrome model of addiction: Multiple expressions, common etiology. Harv Rev Psychiatry 12: 367-374.

16. Griffiths MD (2005)A 'components' model of addiction within a biopsychosocial framework. Journal of Substance Use 10: 191-197.
This article was originally published in a special issue, Substance and Behavioral Addictions handled by Editor(s). Dr. Roxana Carare, University of Southampton, UK; Dr. Daria J. Kuss, Nottingham Trent University, UK.
Submit your next manuscript and get advantages of OMICS Group submissions

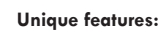

- User friendly/feasible website-translation of your paper to 50 world's leading languages Audio Version of published paper

- Digital articles to share and explore

Special features:

200 Open Access Journals

- 15,000 editorial team

21 days rapid review process

Quality and quick editorial, review and publication processing

Indexing at PubMed (partial), Scopus, DOAJ, EBSCO, Index Copernicus and Google Scholar etc

Sharing Option: Social Networking Enabled

Authors, Reviewers and Editors rewarded with online Scientific Credits

Better discount for your subsequent articles

Submit your manuscript at: http://www.omicsonline.org/submission 